Pacific Journal of Mathematic 


\title{
SOME CONVERGENCE THEOREMS IN BANACH ALGEBRAS
}

\author{
J. J. KoLIHA
}

This paper is concerned with finding necessary and sufficient conditions for the convergence of the sequence $\left\{f_{n}(a)\right\}$ of elements of Banach algebra, where $\left\{f_{n}\right\}$ is a sequence of analytic functions imitating the behavior of the sequence of integral powers. In particular, it is shown that the sequence $\left\{a^{n}\right\}$ converges iff the spectrum of a (with the possible exception of the point $\lambda=1$ ) lies in the open unit disc and $\lambda=1$ is a pole of $(\lambda-a)^{-1}$ of order $\leqq 1$.

The spectral characterization of power convergent operators on Hilbert (or Banach) spaces given in [3] can be extended to elements of Banach algebras, however, the methods of [3], based on the direct decomposition of the underlying space are no longer applicable. The main purpose of this note is to prove certain convergence theorems in a complex unital Banach algebra $\mathscr{A}$, which will yield, as a special case, the following result (cf. [3] for operator formulation):

Theorem 0. Let $a \in \mathscr{A}$. The sequence $\left\{a^{n}\right\}$ converges iff

(i) $\mathrm{Sp}(a)-\{1\}$ lies in the open unit disc, and

(ii) 1 is a pole of $(\lambda-a)^{-1}$ of order $\leqq 1$.

(Sp (a) denotes the spectrum of the element $a \in \mathscr{A}$.) Rephrasing the theorem slightly, we may say that the sequence $\left\{f_{n}(a)\right\}$ converges in $\mathscr{A}$ iff $\left\{f_{n}(\lambda)\right\}$ converges uniformly to zero on $\operatorname{Sp}(a)-\{1\}$ and 1 is a pole of $(\lambda-a)^{-1}$ of order $\leqq 1$, where $f_{n}(\lambda)=\lambda^{n}$. In the sequel, we shall consider functions more general than $f_{n}(\lambda)=\lambda^{n}$, employing the operational calculus in a Banach algebra (cf. [2, Chapter V] or [1, Chapter VII]).

A complex function $f$ of complex variable will be called (in this paper) power-like if the following two conditions are fulfilled:

(1) $f$ is analytic in a $\operatorname{disc} U(f)=\{\lambda:|\lambda|<\delta\}, \delta>1$,

(2) $(1-f(\lambda))(1-\lambda)^{-1}$ has a removable singularity at $\lambda=1$.

A sequence $\left\{f_{n}\right\}$ of power-like functions will be called admissible for $\mathscr{A}$ if

(3) $(\boldsymbol{1}-x) f_{n}(x) \rightarrow 0$ for each $x \in \mathscr{A}$ with $\operatorname{Sp}(x) \subset \bigcap_{n} \Delta\left(f_{n}\right)$ and with $\left\{f_{n}(x)\right\}$ convergent,

and 


$$
f_{n}(0) \longrightarrow 0 \text {. }
$$

We offer some examples of sequences of power-like functions admissible for any algebra $\mathscr{A}$ :

(i) The very prototype of such sequences, the sequence $\left\{\lambda^{n}\right\}$ of integral powers of $\lambda$.

(ii) The sequence of Cesàro means of the integral powers,

$$
\frac{1}{n}\left(1+\lambda+\cdots+\lambda^{n-1}\right) .
$$

(iii) Let $\left\{\gamma_{n}\right\}$ be any sequence of complex numbers convergent to 0 . We may define $f_{n}$ inductively by one of the following formulae [5, Proposition 2.1]:

$$
\begin{array}{ll}
f_{n+1}(\lambda)=\left(1-\gamma_{n}\right) \lambda f_{n}(\lambda)+\gamma_{n}, & f_{1}(\lambda) \equiv 1, \\
f_{n+1}(\lambda)=\left(1-\gamma_{n}\right) \lambda f_{n}(\lambda)+\gamma_{n} \lambda, & f_{1}(\lambda) \equiv 1, \\
f_{n+1}(\lambda)=\left(\left(1-\gamma_{n}\right) \lambda+\gamma_{n}\right) f_{n}(\lambda), & f_{1}(\lambda) \equiv 1 .
\end{array}
$$

In each of the three formulae, $f_{n}$ is a polynomial of the form

$$
f_{n}(\lambda)=1+(\lambda-1) g_{n}(\lambda),
$$

where $g_{n}$ is a polynomial of degree $\leqq n-2$.

We observe that, by virtue of (2), each power-like function $f_{n}$ can be written in the form (5) with $g_{n}$ analytic in $\Delta\left(f_{n}\right)$.

Theorem 1. Let $\left\{f_{n}\right\}$ be an admissible sequence of power-like functions, and let $\operatorname{Sp}(\alpha) \subset \bigcap_{n} \Delta\left(f_{n}\right)$. Then $\left\{f_{n}(\alpha)\right\}$ converges iff

$$
a=p+c,
$$

where

$$
p^{2}=p, \quad p c=c p=0, \quad f_{n}(c) \longrightarrow 0 .
$$

Proof. Suppose first that $f_{n}(a) \rightarrow p$. Then $(1-a) p=p(1-a)=$ 0 in view of (3), and $a p=p a=p$. More generally,

$$
a^{k} p=p a^{k}=p, \quad k \geqq 0 .
$$

For each complex $\lambda \notin \operatorname{Sp}(a) \cup\{1\}$,

$$
(\lambda-a)^{-1} p=(\lambda-1)^{-1} p .
$$

This shows that $p=0$ whenever $\lambda=1$ is a regular point for $(\lambda-a)^{-1}$. Let $C_{n}$ be a contour in $\Delta\left(f_{n}\right)$ enclosing $\operatorname{Sp}(\alpha) \cup\{1\} . \quad\left(C_{n}\right.$ is a boundary of an open set $U_{n}(\supset \mathrm{Sp}(a) \cup\{1\})$ consisting of a finite number 
of closed rectifiable Jordan curves positively oriented with respect to $U_{n}$.) Then

$$
\begin{aligned}
p f_{n}(a) & =\frac{1}{2 \pi i} \int_{C_{n}} f_{n}(\lambda)(\lambda-a)^{-1} p d \lambda \\
& =\frac{p}{2 \pi i} \int_{C_{n}} f_{n}(\lambda)(\lambda-1)^{-1} d \lambda=p f_{n}(1)=p ;
\end{aligned}
$$

we have used (9), and then (5) to get $f_{n}(1)=1$. Consequently,

$$
p^{2}=p \lim _{n \rightarrow \infty} f_{n}(a)=\lim _{n \rightarrow \infty} p f_{n}(a)=p .
$$

More generally, $p^{k}=p$ for each $k \geqq 1$, and induction (utilizing (8)) yields

$$
(a-p)^{k}=a^{k}-p, \quad k \geqq 1 .
$$

Let us write $\alpha_{n k}$ for $f_{n}^{(k)}(0) / k !$, and set $c=a-p$. Then

$$
\begin{aligned}
f_{n}(a)-\left(1-f_{n}(0)\right) p & =\sum_{k=0}^{\infty} \alpha_{n k} a^{k}-\left[\sum_{k=1}^{\infty} \alpha_{n k}\right] p \\
& =\sum_{k=0}^{\infty} \alpha_{n k}(a-p)^{k}=f_{n}(a-p)=f_{n}(c),
\end{aligned}
$$

using the analyticity of $f_{n}$ on $\Delta\left(f_{n}\right)(\supset \mathrm{Sp}(a))$, and the identity (10). Therefore, $f_{n}(c)$ is defined, and

$$
f_{n}(c)=\left(f_{n}(a)-p\right)+f_{n}(0) p \longrightarrow 0
$$

by virtue of (4). Finally,

$$
c p=p c=p(a-p)=p a-p^{2}=0 .
$$

Assume, conversely, that (6) and (7) hold. Then

$$
a^{k}=(p+c)^{k}=p+c^{k},
$$

and

$$
\begin{aligned}
f_{n}(a) & =f_{n}(p+c)=\sum_{k=0}^{\infty} \alpha_{n k}(p+c)^{k}=f_{n}(0)+\sum_{k=1}^{\infty} \alpha_{n k} c^{k}+\left[\sum_{k=1}^{\infty} \alpha_{n k}\right] p \\
& =f_{n}(c)+\left(1-f_{n}(0)\right) p \longrightarrow p \text { as } n \longrightarrow \infty .
\end{aligned}
$$
result.

If $f_{n}(\lambda)=\lambda^{n}$ in the preceding theorem, we obtain the following

CoROLlaRY. $\left\{a^{n}\right\}$ converges iff $a=p+c$, where

$$
p^{2}=p, \quad p c=c p=0, \quad \lim _{n \rightarrow \infty}\left\|c^{n}\right\|^{1 / n}<1 .
$$

The following theorem gives a sufficient condition for the con- 
vergence of $\left\{f_{n}(a)\right\}$ if $\left\{f_{n}\right\}$ is an admissible sequence of power-like functions. A brief glance at Theorem 3 will tell the reader how far this condition is from being also necessary. The proof of the theorem could be based on our Theorem 1, on Theorem 5.5.1 [1, p. 174], and on Theorem VII.3.22 [2, p. 576]. We give a direct proof which appears to be fairly simple and straightforward.

THEOREM 2. Let $\left\{f_{n}\right\}$ be an admissible sequence of power-like functions. If

(i) all $f_{n}$ are analytic and uniformly convergent to zero on a fixed open neighborhood $\Omega$ of $\operatorname{Sp}(a)-\{1\}$,

and

(ii) 1 is a pole of $(\lambda-a)^{-1}$ of order $\leqq 1$, then $\left\{f_{n}(a)\right\}$ converges.

Proof. For a certain $\delta>0$,

$$
(\lambda-\alpha)^{-1}=(\lambda-1)^{-1} p+h(\lambda), \quad 0<|\lambda-1|<\delta,
$$

where $h$ is analytic in an open neighborhood of $\operatorname{Sp}(a)$. We can select a contour $C$ in $\Omega$ enclosing $\operatorname{Sp}(a)-\{1\}$, and for each $n$ we can find a positively oriented circle $C_{n}=\{\lambda:|\lambda-1|=\varepsilon<\delta\}$ that misses $C$ and such that $f_{n}$ is analytic in an open neighborhood of $C_{n}$. Using (11), we get

$$
\begin{aligned}
f_{n}(\alpha)-p= & \frac{1}{2 \pi i} \int_{C \div C_{n}} f_{n}(\lambda)(\lambda-a)^{-1} d \lambda-\frac{1}{2 \pi i} \int_{C_{n}}(\lambda-a)^{-1} d \lambda \\
= & \frac{1}{2 \pi i} \int_{C} f_{n}(\lambda)(\lambda-a)^{-1} d \lambda+\frac{1}{2 \pi i} \int_{C_{n}}\left(f_{n}(\lambda)-1\right)(\lambda-a)^{-1} d \lambda \\
= & \frac{1}{2 \pi i} \int_{C} f_{n}(\lambda)(\lambda-a)^{-1} d \lambda+\frac{p}{2 \pi i} \int_{C_{n}} g_{n}(\lambda) d \lambda \\
& +\frac{1}{2 \pi i} \int_{C_{n}}\left(f_{n}(\lambda)-1\right) h(\lambda) d \lambda \\
= & \frac{1}{2 \pi i} \int_{C} f_{n}(\lambda)(\lambda-a)^{-1} d \lambda,
\end{aligned}
$$

where $g_{n}$ is specified in (5). Hence

$$
\left\|f_{n}(a)-p\right\| \leqq \frac{1}{2 \pi} \sup _{\lambda \in C}\left\|f_{n}(\lambda)(\lambda-a)^{-1}\right\| \cdot l(C) \leqq K \sup _{\lambda \in \Omega}\left|f_{n}(\lambda)\right|,
$$

with

$$
K=\frac{l(C)}{2 \pi} \sup _{\lambda \in C}\left\|(\lambda-a)^{-1}\right\|<+\infty, \quad l(C) \text { the length of } C .
$$

This gives $f_{n}(a) \rightarrow p$, and completes the proof. 
Theorem 2 has a partial converse which will be proved after the following two auxiliary results.

LeMmA 1. If $x_{n} x \rightarrow 1$ and $x x_{n} \rightarrow 1$, then $x$ is invertible, and $x_{n} \rightarrow x^{-1}$.

Proof. Let $N$ be a fixed positive integer such that

$$
\left\|1-x_{N} x\right\|<\frac{1}{2}
$$

For each $\varepsilon>0$ we can find a positive integer $n_{0}$ such that

$$
\left\|x x_{n}-x x_{m}\right\|<\varepsilon /\left(2\left\|x_{N}\right\|\right) \quad \text { whenever } n, m>n_{0} .
$$

Since

$$
x_{n}-x_{m}=\left(1-x_{N} x\right)\left(x_{n}-x_{m}\right)+x_{N}\left(x x_{n}-x x_{m}\right),
$$

we get

$$
\left\|x_{n}-x_{m}\right\|<\frac{1}{2}\left\|x_{n}-x_{m}\right\|+\frac{1}{2} \varepsilon,
$$

and

$$
\left\|x_{n}-x_{m}\right\|<\varepsilon \quad \text { whenever } n, m>n_{0} .
$$

Hence $x_{n} \rightarrow y$ for some $y \in \mathscr{A}$, and $y x=x y=1$.

LEMma 2. Let $\left\{f_{n}\right\}$ be an arbitrary sequence of power-like functions with $\bigcap_{n} \Delta\left(f_{n}\right) \supset \mathrm{Sp}(c)$. If $f_{n}(c) \rightarrow 0$, then 1 is a regular point for $(\lambda-c)^{-1}$, and

$$
g_{n}(c) \longrightarrow(1-c)^{-1},
$$

with $g_{n}$ defined in (5).

Proof. If $f_{n}(c) \rightarrow 0$, then

$$
g_{n}(c)(1-c)=(1-c) g_{n}(c) \longrightarrow 1 .
$$

The result follows on taking $x_{n}=g_{n}(c)$ and $x=1-c$ in Lemma 1 .

A special case of Lemma 1 for the algebra of bounded linear operators on a Banach space and with $f_{n}$ polynomials of a certain form has been proved in [4, Proposition 5]. A particularly simple form of Lemma 2 is the following well known result: If $c^{n} \rightarrow 0$, then the series $\sum_{n} c^{n}$ converges to $(1-c)^{-1}$. Also:

$$
n^{-1} c^{n}+1 \longrightarrow 0 \Longrightarrow n^{-1}\left(1+c+\cdots+c^{n-1}\right) \longrightarrow(1-c)^{-1},
$$




$$
n^{-1}\left(1+c+\cdots+c^{n-1}\right) \longrightarrow 0 \Longrightarrow \sum_{k=0}^{n-2} \frac{n-k-1}{n} c^{k} \longrightarrow(1-c)^{-1},
$$

etc.

THEOREM 3. Let $\left\{f_{n}\right\}$ be an admissible sequence of power-like functions with $\bigcap_{n} \Delta\left(f_{n}\right) \supset \operatorname{Sp}(a)$. If $\left\{f_{n}(\alpha)\right\}$ converges, then and

(i) $f_{n}(\lambda) \rightarrow 0$ uniformly on $\operatorname{Sp}(a)-\{1\}$,

(ii) 1 is a pole of $(\lambda-a)^{-1}$ of order $\leqq 1$.

Proof. Suppose $f_{n}(a) \rightarrow p$. The elements $p$ and $c=a-p$ satisfy the conditions (6) and (7), in particular, $f_{n}(c) \rightarrow 0$. By Lemma 2, 1 is a regular point for $(\lambda-c)^{-1}$, and hence the function

$$
h(\lambda)=(\lambda-c)^{-1}(1-p)
$$

is analytic in a certain open neighborhood of 1 . The function

$$
u(\lambda)=h(\lambda)+(\lambda-1)^{-1} p
$$

has a pole of order $\leqq 1$ at $\lambda=1$. The elements $\lambda-a$ and $u(\lambda)$ commute (whenever the latter is defined). Moreover,

$$
\begin{aligned}
(\lambda-a) u(\lambda) & =(\lambda-a)(\lambda-c)^{-1}(1-p)+(\lambda-1)^{-1}(\lambda-a) p \\
& =(\lambda-c)^{-1}(\lambda(1-p)-c)+p \\
& =(\lambda-c)^{-1}(\lambda(1-p)-c+(\lambda-c) p) \\
& =(\lambda-c)^{-1}(\lambda-c) \\
& =1 .
\end{aligned}
$$

Hence, $u(\lambda)=(\lambda-a)^{-1}$, and

$$
(\lambda-a)^{-1}=(\lambda-c)^{-1}(1-p)+(\lambda-1)^{-1} p .
$$

The identity (12) shows that

$$
\operatorname{Sp}(a)-\{1\}=\operatorname{Sp}(c) \text {. }
$$

Finally, $f_{n}(c) \rightarrow 0$ implies $f_{n}(\lambda) \rightarrow 0$ uniformly on $\operatorname{Sp}(c)$ [1, p. 584], and the proof is complete.

\section{REFERENCES}

1. N. Dunford and J. T. Schwartz, Linear Operators I, Interscience, New York, 1957.

2. E. Hille and R. S. Phillips, Functional Analysis and Semigroups, AMS Colloquium Publications XXXI, AMS, Providence, Rhode Island, 1957.

3. J. J. Koliha, Convergent and stable operators and their generalization, J. Math. Anal. Appl., 43 (1973), 778-794. 
4. J. J. Koliha, Ergodic theory and averaging iterations, Canad. J. Math., 25 (1973), 14-23.

5. The solution of linear equations in normed spaces by averaging iteration, SIAM J. Math. Anal., 5 (1974).

Received August 7, 1973 and in revised form November 28, 1973.

UNIVERSity OF MelboURne 



\section{PACIFIC JOURNAL OF MATHEMATICS}

EDITORS

RICHARD ARens (Managing Editor)

University of California

Los Angeles, California 90024

\section{R. A. Beaumont}

University of Washington

Seattle. Washington 98105

\section{J. DugundjI}

Department of Mathematics University of Southern California Los Angeles, California 90007

D. Gilbarg and J. Milgram

Stanford University

Stanford. California 94305

\section{ASSOCIATE EDITORS}
E. F. BECKENBACH
B. H. NEUMANN
F. WOLF
K. Yoshida

\section{SUPPORTING INSTITUTIONS}

\author{
UNIVERSITY OF BRITISH COLUMBIA \\ CALIFORNIA INSTITUTE OF TECHNOLOGY \\ UNIVERSITY OF CALIFORNIA \\ MONTANA STATE UNIVERSITY \\ UNIVERSITY OF NEVADA \\ NEW MEXICO STATE UNIVERSITY \\ OREGON STATE UNIVERSITY \\ UNIVERSITY OF OREGON \\ OSAKA UNIVERSITY
}

\author{
UNIVERSITY OF SOUTHERN CALIFORNIA \\ STANFORD UNIVERSITY \\ UNIVERSITY OF TOKYO \\ UNIVERSITY OF UTAH \\ WASHINGTON STATE UNIVERSITY \\ UNIVERSITY OF WASHINGTON

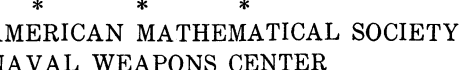

The Supporting Institutions listed above contribute to the cost of publication of this Journal, but they are not owners or publishers and have no responsibility for its content or policies.

Mathematical papers intended for publication in the Pacific Journal of Mathematics should be in typed form or offset-reproduced, (not dittoed), double spaced with large margins. Underline Greek letters in red, German in green, and script in blue. The first paragraph or two must be capable of being used separately as a synopsis of the entire paper. Items of the bibliography should not be cited there unless absolutely necessary, in which case they must be identified by author and Journal, rather than by item number. Manuscripts, in duplicate if possible, may be sent to any one of the four editors. Please classify according to the scheme of Math. Rev. Index to Vol. 39. All other communications to the editors should be addressed to the managing editor, or Elaine Barth, University of California, Los Angeles, California, 90024.

100 reprints are provided free for each article, only if page charges have been substantially paid Additional copies may be obtained at cost in multiples of 50 .

The Pacific of Journal Mathematics is issued monthly as of January 1966. Regular subscription rate: $\$ 72.00$ a year (6 Vols., 12 issues). Special rate: $\$ 36.00$ a year to individual members of supporting institutions.

Subscriptions, orders for back numbers, and changes of address should be sent to Pacific Journal of Mathematics, 103 Highland Boulevard, Berkeley, California, 94708.

\section{PUBLISHED BY PACIFIC JOURNAL OF MATHEMATICS, A NON-PROFIT CORPORATION}

Printed at Kokusai Bunken Insatsusha (International Academic Printing Co., Ltd.), 270, 3-chome Totsuka-cho. Shinjuku-ku, Tokyo 160. Japan.

Copyright (C) 1973 by Pacific Journal of Mathematics Manufactured and first issued in Japan 


\section{Pacific Journal of Mathematics}

\section{Vol. 52, No. $2 \quad$ February, 1974}

Harm Bart, Spectral properties of locally holomorphic vector-valued functions .....

J. Adrian (John) Bondy and Robert Louis Hemminger, Reconstructing infinite

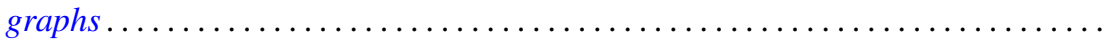

Bryan Edmund Cain and Richard J. Tondra, Biholomorphic approximation of planar

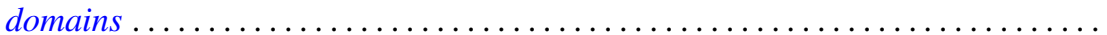

Richard Carey and Joel David Pincus, Eigenvalues of seminormal operators,

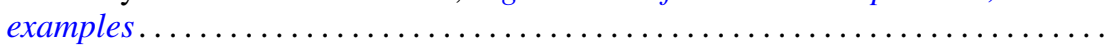

Tyrone Duncan, Absolute continuity for abstract Wiener spaces . . . . . . . . . . . . Joe Wayne Fisher and Louis Halle Rowen, An embedding of semiprime

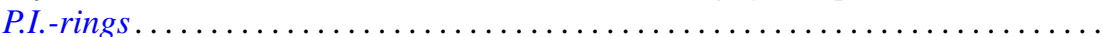

Andrew S. Geue, Precompact and collectively semi-precompact sets of semi-precompact continuous linear operators. . . . . . . . . . . . . . . .

Charles Lemuel Hagopian, Locally homeomorphic $\lambda$ connected plane continua ..... . Darald Joe Hartfiel, A study of convex sets of stochastic matrices induced by

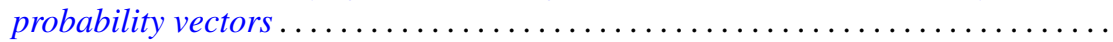

Yasunori Ishibashi, Some remarks on high order derivations $\ldots \ldots \ldots \ldots \ldots \ldots \ldots$ Donald Gordon James, Orthogonal groups of dyadic unimodular quadratic forms.

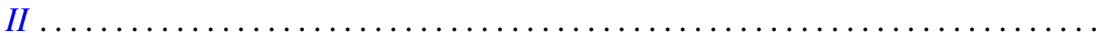

Geoffrey Thomas Jones, Projective pseudo-complemented semilattices . . . . . . . . . Darrell Conley Kent, Kelly Denis McKennon, G. Richardson and M. Schroder,

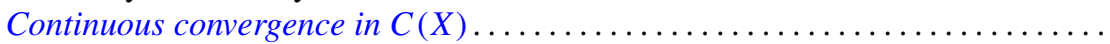

J. J. Koliha, Some convergence theorems in Banach algebras ...

Tsang Hai Kuo, Projections in the spaces of bounded linear oper

George Berry Leeman, Jr., A local estimate for typically real functions . .

475

Andrew Guy Markoe, A characterization of normal analytic spaces by the

homological codimension of the structure sheaf .........

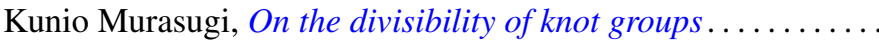

John Phillips, Perturbations of type I von Neumann algebras.

Billy E. Rhoades, Commutants of some quasi-Hausdorff matrices . .

David W. Roeder, Category theory applied to Pontryagin duality

Maxwell Alexander Rosenlicht, The nonminimality of the differential closure .

Peter Michael Rosenthal, On an inversion theorem for the general Mehler-Fock transform pair.

Alan Saleski, Stopping times for Bernoulli automorphisms

John Herman Scheuneman, Fundamental groups of compact complete locally affine complex surfaces. II. ........................

Vashishtha Narayan Singh, Reproducing kernels and operators with a cyclic vector. I. .

Peggy Strait, On the maximum and minimum of partial sums of random variables.

J. L. Brenner, Maximal ideals in the near ring of polynomials modulo 2 .

Ernst Gabor Straus, Remark on the preceding paper: "Ideals in near rings of polynomials over a field" ..........................

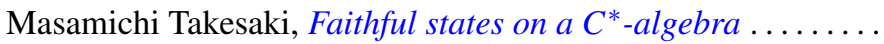

R. Michael Tanner, Some content maximizing properties of the regular simplex.

Andrew Bao-hwa Wang, An analogue of the Paley-Wiener theorem for certain

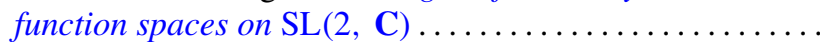

